\title{
Reproducibility of a 5-repetition maximum strength test in older adults
}

\author{
Sascha Gail ${ }^{\mathrm{a}, *}$, Steffen Rodefeld ${ }^{\mathrm{b}}$ and Stefan Künzell ${ }^{\mathrm{a}}$ \\ ${ }^{\mathrm{a}}$ Institute of Sports Science/Sports Centre, Augsburg University, Augsburg, Germany \\ ${ }^{\mathrm{b}}$ Therapy and Training Department, Hessingpark-Clinic GmbH, Augsburg, Germany
}

\begin{abstract}
.
BACKGROUND AND OBJECTIVE: Multiple repetition maximum (M-RM) strength tests are suitable alternatives to the 1repetition maximum (1-RM) strength test, particularly in the elderly. In comparison to the 1-RM strength test the research about the reproducibility of M-RM strength tests is very limited, leading to a lack of standardized test protocols for M-RM strength tests. Therefore, the aim of this study was to assess the test-retest reproducibility of a 5-repetition maximum (5-RM) strength test in older adults.

METHODS: After a short preparation session, 28 healthy elderly people older than 60 years (14 men, 14 women) and with at least 3 months strength training experience passed a 5-RM strength test. The test included exercises for the upper body, namely bench press and seated row, and were performed twice within 7 days on the same day of the week at the same time of the day.

RESULTS: Significant differences between test and retest $(p<0.05)$ in $2 / 6$ instances provide evidence of practice-based improvement (PBI). A very high intraclass correlation coefficient (ICC $>0.90 ; p<0.001$ ) was found for the total sample as well as for both sub-samples (men, women). The coefficients of variation were very low and ranged between 0.7 and $2.8 \%$. The high test-retest reproducibility was also demonstrated by the narrow limits of agreements, the very little standard errors of measurements and the minimal smallest real differences.

CONCLUSION: The present study confirms the reproducibility of the 5-RM strength test for upper body exercises in older adults with strength training experience. The 5-RM strength test is a reliable and simple measurement and can be used in sports practice for theoretical and practical purposes.
\end{abstract}

Keywords: Maximum strength, strength diagnostics, strength training, training load

\section{Introduction}

Strength training plays an important role for elderly people as they often show a loss of skeletal muscle mass and muscle function with aging. Among other effects, this loss results in reduced activities in daily life and increases the risk of falls [1]. It is well known that strength training is an effective prevention to counter-

* Corresponding author: Sascha Gail, Institute of Sports Science/ Sports Centre, Augsburg University, Universitätsstraße 3, 86135 Augsburg, Germany. Tel.: +49 821598 2827; Fax: +49 821598 2828; E-mail: sascha.gail@ sport.uni-augsburg.de. act the degeneration process in aging [2-4]. In order to support strength training an adequate strength test is needed. The main purposes of strength tests are quantifying the level of muscle strength, evaluating strength training programs and determining loads for strength training.

Due to simplicity and cost efficiency, the 1-repetition maximum (1-RM) strength test is considered as the gold standard method for assessing muscle strength in non-laboratory settings $[5,6]$. The $1-\mathrm{RM}$ is defined as the maximum weight a person can lift once with the correct lifting technique [7-9]. Previous studies have confirmed the high reproducibility of the 1-RM strength test among different target groups [6,10,11]. 
Rydwik et al. [12] demonstrated the high reproducibility of this strength testing method also in older adults.

However, conducting a 1-RM strength test is somewhat critical, especially concerning elderly people [13]. The 1-RM strength test is associated with high physical exertion for muscles, connective tissues and joints [7]. Besides, determining the 1-RM involves a high risk for injuries [5,8]. In addition, various studies show that the 1-RM is inappropriate for specifying load for strength training $[14,15]$. For example, the frequently propagated linear 1-RM-repetition relationship is curvilinear and strongly influenced by confounding factors like strength training experience and type of exercise [7]. Therefore, the classical approach to derive loads for strength training as a certain percentage of the 1-RM often leads to an overestimated or insufficient load.

Suitable alternatives to the 1-RM strength test, particularly in the elderly, are multiple repetition maximum (M-RM) strength tests [5,7]. The M-RM is defined as the maximum weight a person can lift with the correct lifting technique a certain number of repetitions [7]. For instance, the 5-repetition maximum (5-RM) is the maximum weight a person can lift five times with the correct lifting technique. The M-RM strength test can be used for the same purposes as the 1-RM strength test. Furthermore, the M-RM strength test is suitable for prescribing the intensity in strength training [16].

Nevertheless, limited research of the reproducibility of M-RM strength tests has been conducted. Consequently, there is a lack of standardized test protocols for M-RM strength tests. Taylor and Fletcher [16] as well as Gail and Künzell [17] investigated the reproducibility of different M-RM strength tests in young and middle-aged adults. To our best knowledge, there are no studies about the reproducibility of M-RM strength tests in older adults. Therefore, the aim of this study was to assess the test-retest reproducibility of the 5-RM strength test of Gail and Künzell [17] in older adults. We hypothesized that the reproducibility would not be extremely different between older adults and young and middle-aged adults. Accordingly, this would mean that the presented 5-RM strength test is also suitable for elderly people.

\section{Methods}

Twenty-eight healthy elderly people (14 men, 14 women) participated voluntarily in this study and gave their written informed consent. The participants were

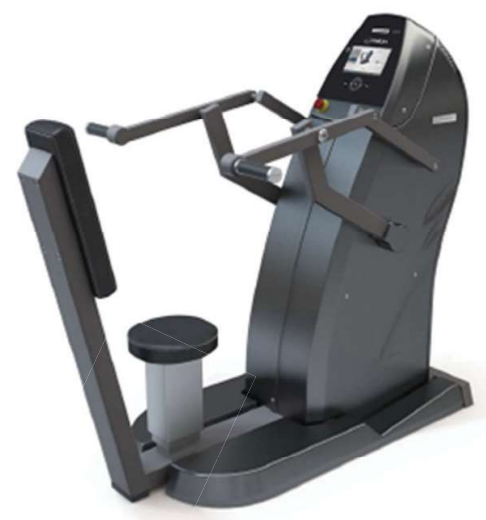

Fig. 1. Exercise bench press.

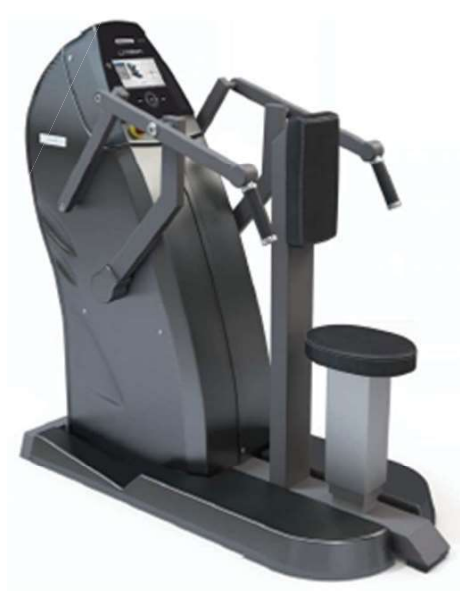

Fig. 2. Exercise seated row.

older than 60 years and had no exercise contraindications. The age was $70.1 \pm 5.5$ years, the body weight was $170.3 \pm 8.9 \mathrm{~cm}$ and the body weight was $77.5 \pm$ $18.5 \mathrm{~kg}$. All participants had at least 3 months strength training experience. All the procedures undertaken in this study were approved by the local ethics board of the University of Augsburg and are in compliance with the Declaration of Helsinki.

In the first preparatory session the participants were introduced to the exercise equipment (miltronic Premium Med; Milon industries GmbH, Emersacker, Germany) and were introduced on how to correctly perform the exercise. The miltronic Premium Med devices inform the participants during their exercise by visual feedback about the correct range of motion (ROM) and the appropriate speed of movements (SOM) as well as the time of movement turnaround. The appropriate adjustment of the exercise equipment was controlled by a chip card providing and saving the adjustment data. 
Table 1

Values of 5-RM (mean \pm standard deviation) as well as limits of agreements (LOA) in kg and Wilcoxon signed-rank tests for test and retest

\begin{tabular}{|c|c|c|c|c|c|c|}
\hline & & Test & Retest & $\mathrm{LOA}$ & $Z$ & $p$ \\
\hline $\begin{array}{l}\text { Total } \\
(n=28)\end{array}$ & $\begin{array}{l}\text { Bench press } \\
\text { Seated row }\end{array}$ & $\begin{array}{l}42.0 \pm 15.7 \\
47.0 \pm 17.5\end{array}$ & $\begin{array}{l}42.7 \pm 16.0 \\
48.2 \pm 18.1\end{array}$ & $\begin{array}{l}-0.77,2.20 \\
-0.48,2.98\end{array}$ & $\begin{array}{l}-1.633 \\
-2.646\end{array}$ & $\begin{array}{l}0.102 \\
0.008\end{array}$ \\
\hline $\begin{array}{l}\text { Men } \\
(n=14)\end{array}$ & $\begin{array}{l}\text { Bench press } \\
\text { Seated row }\end{array}$ & $\begin{array}{l}52.9 \pm 14.8 \\
60.7 \pm 14.1\end{array}$ & $\begin{array}{l}53.9 \pm 14.8 \\
62.5 \pm 14.5\end{array}$ & $\begin{array}{l}-1.40,3.55 \\
-0.69,4.26\end{array}$ & $\begin{array}{l}-1.342 \\
-2.236\end{array}$ & $\begin{array}{l}0.180 \\
0.025\end{array}$ \\
\hline $\begin{array}{l}\text { Women } \\
(n=14)\end{array}$ & $\begin{array}{l}\text { Bench press } \\
\text { Seated row }\end{array}$ & $\begin{array}{l}31.1 \pm 5.9 \\
33.2 \pm 5.4\end{array}$ & $\begin{array}{l}31.4 \pm 6.3 \\
33.9 \pm 5.3\end{array}$ & $\begin{array}{l}-0.14,0.85 \\
-0.28,1.70\end{array}$ & $\begin{array}{l}-1.000 \\
-1.414\end{array}$ & $\begin{array}{l}0.317 \\
0.157\end{array}$ \\
\hline
\end{tabular}

Table 2

Intraclass correlation coefficients (ICC) with $95 \%$ confidence intervals (CI), coefficients of variation (CV), standard error of measurements (SEM) and smallest real differences (SRD) of 5-RM for test and retest

\begin{tabular}{|c|c|c|c|c|c|}
\hline & & ICC & $\mathrm{CV}$ & SEM & SRD \\
\hline Total & Bench press & 1.00 (CI: 0.99-1.00) & $1.8 \%$ & $0.05 \mathrm{~kg}$ & $0.15 \mathrm{~kg}$ \\
\hline$(n=28)$ & Seated row & 1.00 (CI: 0.99-1.00) & $1.9 \%$ & $0.06 \mathrm{~kg}$ & $0.17 \mathrm{~kg}$ \\
\hline Men & Bench press & 0.99 (CI: $0.97-1.00)$ & $2.8 \%$ & $0.13 \mathrm{~kg}$ & $0.35 \mathrm{~kg}$ \\
\hline$(n=14)$ & Seated row & 0.99 (CI: 0.97-1.00) & $2.1 \%$ & $0.13 \mathrm{~kg}$ & $0.37 \mathrm{~kg}$ \\
\hline Women & Bench press & 0.99 (CI: 0.96-1.00) & $0.7 \%$ & $0.03 \mathrm{~kg}$ & $0.08 \mathrm{~kg}$ \\
\hline$(n=14)$ & Seated row & 0.97 (CI: $0.90-0.99$ ) & $1.6 \%$ & $0.09 \mathrm{~kg}$ & $0.25 \mathrm{~kg}$ \\
\hline
\end{tabular}

Changes of the adjustment were only possible if the tester was present. After a break for few days, the participants passed the 5-RM strength test with both exercises, namely bench press (Fig. 1) and seated row (Fig. 2), twice within 7 days on the same day of the week. To avoid negative impacts of circadian rhythm on the test results $[18,19]$, test and retest were performed at the same time of the day. In order to identify potential differences in fatigue and motivation between test and retest the physical and mental conditioning was documented by a self-administered questionnaire. Thus, participants had to document their level of fatigue and motivation on a four-point scale. All tests were instructed and supervised by the same tester. The warm-up comprised 10 min moderate cycling ( $1 \mathrm{~W}$ per kilogram body weight at 60-80 rpm) and one set of the test exercises (ten repetitions at $50 \%$ of the estimated 10-RM based on the individual assessment of the respective participant). Owing to the negative effects on strength performance [20-22] and the lack of evidence for injury prevention [23], stretching was not included. All participants started with bench press followed by seated row. The take-off weight was based on the individual assessment of the respective participant. The same was true for the extent of increase (successful test trial which means that the participant could manage to lift the weight five times with the correct exercise technique, controlled by the tester and the device) or decrease (unsuccessful test trial which means that the participant could not manage to lift the weight five times with the correct exercise technique) after each test trial. The break duration was $2 \mathrm{~min}$. Each partic- ipant was tested separately and requested to achieve maximal performance.

All statistical analyses were carried out using the statistical software IBM ${ }^{\circledR}$ SPSS ${ }^{\circledR}$ Statistics version 22 (IBM $^{\circledR}$ Corp., Armonk, NY, USA). Results are shown as means of \pm standard deviation. The normal distribution of the variables was tested by a Shapiro Wilk test. In accordance with the recommendations of Hopkins [24] three parameters were raised. Wilcoxon signed-rank tests (variables were not normally distributed) were carried out to analyze whether significant differences existed between test and retest. Intraclass correlation coefficients (ICC) [25,26] were calculated to determine test-retest correlation. For this, the ICC 1,2 (one-way random, average measure) was used because test and retest were directed by the same researcher [27]. The typical error was estimated by the coefficient of variation (CV). For this purpose, the $\mathrm{CV}$ was firstly calculated for each single participant (the used formula was: standard deviation of test and retest divided by the mean of test and retest in percent), and then the mean $\mathrm{CV}$ was determined for the complete sample [28,29]. Moreover, the limits of agreement (LOA), the standard error of measurement (SEM) and the smallest real difference (SRD) were considered. An alpha of 5\% was accepted as statistically significant.

\section{Results}

The mean values and standard deviations, LOAs as well as Wilcoxon signed-rank tests for bench press and 
seated row are presented in Table 1 . There were significant differences between test and retest $(p<0.05)$ in part. Table 2 shows ICCs with $95 \%$ confidence intervals (CI), CVs, SEMs and SRDs for both exercises. A very high ICC was found for the total sample as well as for all sub-samples (ICC $>0.90 ; p<0.001$ ). The CVs ranged between 0.7 and $2.8 \%$. The SEMs varied between 0.05 and $0.13 \mathrm{~kg}$ and the SRDs between 0.08 and $0.37 \mathrm{~kg}$.

\section{Discussion}

The aim of the study was to assess the reproducibility of the 5-RM strength test of Gail and Künzell [17] in older adults.

Systematic changes between test and retest in repeated strength tests within short time intervals can result from fatigue or motivational effects as well as from practice-based improvement (PBI) and habituation effects [24]. Fatigue and motivation were standardized due to the chosen research design and monitored by a self-administered questionnaire. In the light of the results, PBI and habituation effects cannot be completely excluded as the mean differences between test and retest were in 2/6 instances significant. Therefore, one brief preparatory session may not be effective enough in the case of a target group of older adults for setting the baseline 5-RM when applying the described approach, which is based on the participants perceived exertion. Owing to this, a second preparatory session should be applied but this requires further research.

The very high retest correlations (ICC) and very low typical errors of measurement $(\mathrm{CV})$ demonstrated the outstanding reproducibility of the 5-RM strength test in older adults independent of their gender. These results connect with the reproducibility studies for the conventional 1-RM strength test which usually leads to comparable high retest correlations independent of the target group [6,10-12]. Moreover, the present results were similar to previous findings $[16,17]$. Taylor and Fletcher [16] examined the reproducibility of an 8-RM strength test for different upper body exercises (chest press, pulldown, overhead press, and seated row) in young adults $(23.0 \pm 1.3$ years $)$ and have indicated ICCs greater than 0.90 and low to very low CVs: 3.4 $10.4 \%$. Gail and Künzell [17] applied a 5-RM strength test and used exactly the same test protocol like the one present in this study. However, in that latter study, the participants were young and middle-aged adults $(31.5 \pm 12.5$ years) and the tests targeted the lower extremities implying leg press and leg curl. Nonetheless, ICCs greater than 0.90 were calculated while the CVs ranged 2.2-4.7\% independent of the participants' (recreational athletes) gender and strength training experience.

Furthermore, the calculated LOAs verified a narrow range of bias between test and retest. With additional consideration of the very few measurement errors assessed by the SEM as well as the identified minimal SRD, these data confirmed the before mentioned results and can be seen as further evidence for the great benefit of the 5-RM strength test in physical exercise of elderly people.

\section{Conclusion}

The present findings confirm the reproducibility of the 5-RM strength test for upper body exercises in older adults with strength training experience. This test is simple to administer and its validity may be extended to include other groups for obtaining a general assessment regarding multiple-muscle multi-joint strength. In comparison to the conventional 1-RM strength test, advantages of the 5-RM strength test are less physical exertion and a lower risk of muscle injury during testing procedures. Further studies should determine the reproducibility of the 5-RM strength test in people with health disorders.

\section{Conflict of interest}

None of the authors has any conflicts of interest associated with this study nor was the study funded by an external body.

\section{References}

[1] Waters DL, Baumgartner RN, Garry PJ, Vellas B. Advantages of dietary, exercise-related, and therapeutic interventions to prevent and treat sarcopenia in adult patients: an update. Clin Interv Aging. 2010; 5: 259-270.

[2] Forbes SC, Little JP, Candow DG. Exercise and nutrition interventions for improving aging muscle health. Endocrine. 2012; 42: 29-38

[3] Roth SM, Ferrell RF, Hurley BF. Strength training for the prevention and treatment of sarcopenia. J Nutr Health Aging. 2000; 4: 143-155.

[4] Roubenoff R. Sarcopenia: a major modifiable cause of frailty in the elderly. J Nutr Health Aging. 2000; 4: 140-142. 
[5] Kraemer WJ, Ratamess NA, Fry AC, French DN. Strength testing: development and evaluation of methodology. In: Maud PJ, Foster C, editors. Physiological assessment of human fitness, $2^{\text {nd }}$ edition. Champaign: Human Kinetics; 2006. p. 119-150.

[6] Levinger I, Goodman C, Hare DL, Jerums G, Toia D, Selig $\mathrm{S}$. The reproducibility of the $1 \mathrm{RM}$ strength test for untrained middle-aged individuals. J Sci Med Sport. 2009; 12: 310-316.

[7] Baechle TR, Earle RW, Wathen D. Resistance training. In: Baechle TR, Earle RW, editors. Essentials of strength training and conditioning, $3^{\text {rd }}$ edition. Champaign: Human Kinetics; 2008. p. 381-412.

[8] Dohoney P, Chromiak JA, Lemire D, Abadie BR, Kovacs C. Prediction of one repetition maximum (1-RM) strength from a 4-6 RM and a 7-10 RM submaximal strength test in healthy young adult males. J Exerc Physiol Online. 2002; 5: 54-59.

[9] Schlumberger A, Schmidtbleicher D. Grundlagen der Kraftdiagnostik in Prävention und Rehabilitation. Manuelle Med. 2000; 38: 223-231.

[10] Abdul-Hameed U, Rangra P, Shareef MY, Hussain ME. Reproducibility of 1-repetition maximum estimation for upper and lower body muscular strength measurement in untrained middle aged type 2 diabetic patients. Asian J Sports Med. 2012; 3: 267-273.

[11] Seo DI, Kim E, Fahs CA, Rossow L, Young K, Ferguson SL, et al. Reproducibility of the one-repetition maximum test based on muscle group and gender. J Sports Sci Med. 2012; 11: 221-225.

[12] Rydwik E, Karlsson C, Frändin K, Akner G. Muscle strength testing with one repetition maximum in the arm/shoulder for people aged $75+-$ test-retest reproducibility. Clin Rehabil. 2007; 21: 258-265.

[13] Reynolds JM, Gordon TJ, Robergs RA. Prediction of one repetition maximum strength from multiple repetition maximum testing and anthropometry. J Strength Cond Res. 2006; 20: 584-592.

[14] Marschall F, Fröhlich M. Überprüfung des Zusammenhangs von Maximalkraft und maximaler Wiederholungszahl bei deduzierten submaximalen Intensitäten. Dtsch Z Sportmed. 1999; 50: 311-315.

[15] Shimano T, Kraemer WJ, Spiering BA, Volek JS, Hatfield DL, Silvestre R, et al. Relationship between the number of repetitions and selected percentages of one repetition maximum in free weight exercises in trained and untrained men. J Strength Cond Res. 2006; 20: 819-823.
[16] Taylor JD, Fletcher JP. Reproducibility of the 8-repetition maximum test in men and women. J Sci Med Sport. 2012; 15 : 69-73.

[17] Gail S, Künzell S. Reproducibility of a 5-repetition maximum strength test in recreational athletes. Dtsch Z Sportmed. 2014; 65: 314-317.

[18] Drust B, Waterhouse J, Atkinson G, Edwards B, Reilly T. Circadian rhythms in sports performance - an update. Chronobiol Int. 2005; 22: 21-44.

[19] Sedliak M, Finni T, Cheng S, Haikarainen T, Häkkinen K. Diurnal variation in maximal and submaximal strength, power and neural activation of leg extensors in men: multiple sampling across two consecutive days. Int J Sports Med. 2008; 29: 217-224.

[20] Behm DG, Button DC, Butt JC. Factors affecting force loss with prolonged stretching. Can J Appl Physiol. 2001; 26: 262272.

[21] Fowles JR, Sale DG, MacDougall JD. Reduced strength after passive stretch of the human plantarflexors. J Appl Physiol. 2000; 89: 1179-1188.

[22] Power K, Behm D, Cahill F, Carroll M, Young W. An acute bout of static stretching: effects on force and jumping performance. Med Sci Sports Exerc. 2004; 36: 1389-1396.

[23] Marschall F, Ruckelshausen B. Dient Dehnen der Verletzungsprophylaxe? Eine qualitative Metaanalyse. Spectrum Sportwiss. 2004; 16: 31-47.

[24] Hopkins WG. Measures of reproducibility in sports medicine and science. Sports Med. 2000; 30: 1-15.

[25] Shrout PE, Fleiss JL. Intraclass correlations: uses in assessing rater reproducibility. Psychol Bull. 1979; 86: 420-428.

[26] Weir JP. Quantifying test-retest reproducibility using the intraclass correlation coefficient and the SEM. J Strength Cond Res. 2005; 19: 231-240.

[27] Rankin G, Stokes M. Reproducibility of assessment tools in rehabilitation: an illustration of appropriate statistical analyses. Clin Rehabil. 1998; 12: 187-199.

[28] O'Hara JP, Thomas A, Seims A, Cooke CB, King RF. Reproducibility of a high-intensity endurance cycling test. Int $\mathrm{J}$ Sports Med. 2012; 33: 18-25.

[29] Requena B, García I, Requena F, Saez-Saez de Villarreal E, Pääsuke M. Reproducibility and validity of a wireless microelectromechanicals based system (keimove ${ }^{\mathrm{TM}}$ ) for measuring vertical jumping performance. J Sports Sci Med. 2012; 11: $115-122$ 